Original Research Paper

\title{
Effect of Sulfonated Acetone Formaldehyde (SAF) on the Firing Resistance and Aggressive Attach of SRC-SF Composite Cement Pastes
}

\author{
${ }^{1}$ Randa M. Osman and ${ }^{2}$ S. Al-Masry \\ ${ }^{1}$ Department of Chemical Engineering and Pilot Plant, National Research Centre, Cairo, Egypt \\ ${ }^{2}$ Department of Chemistry, Faculty of Science, Zagazig University, Zagazig, Egypt
}

Article history

Received: $25-03-2015$

Revised: $12-05-2015$

Accepted: 16-06-2015

Corresponding Author:

Randa M. Osman

Department of Chemical

Engineering and Pilot Plant,

National Research Centre, Cairo, Egypt

E-mail: randa.osman2015@hotmail.com

\begin{abstract}
This work aimed to study the effect of the dosage of laboratory synthesized Sulfonated Acetone Formaldehyde (SAF) on the physicmechanical characteristics and durability of SF-SRC cement pastes immersed in $4 \% \mathrm{MgCl}_{2}$ or $4 \% \mathrm{MgSO}_{4}$ solutions or at elevated temperatures up to $800^{\circ} \mathrm{C}$. The compressive strength of thermally treatment cement pastes with $1.5 \%$ SAF increases up to $600^{\circ} \mathrm{C}$, then decreases up to $800^{\circ} \mathrm{C}$. Presence of $2.0 \%$ SAF works to produce a compact cementing structure, which decreases the accessibility of the penetration of chloride as well as sulphate ion penetration and enhances the durability, hence the total chloride and sulphate contents diminished.
\end{abstract}

Keywords: Accelerator, Firing Resistance, Aggressive Attack, SAF

\section{Introduction}

The durability of cementing materials has been a major concern of civil engineering professionals over the last few decades (Chen and $\mathrm{Wu}, 2013$; Sánchez et al., 2011). Cements with low $\mathrm{C}_{3} \mathrm{~A}$ as well $\mathrm{Ca}(\mathrm{OH})_{2}$ contents generally, exhibit good performance in sulphate environment. It is possible to produce, durable concrete with long-term strength by partial replacement of cement with Supplementary Cementitious Materials (SCMs), such as Fly Ash (FA), Silica Fume (SF) and Granulated Blast-Furnace Slag (GBFS) (Irassar et al., 2000; Shanahan and Zayed, 2007; Montes et al., 2012).

The superior performance of pozzolanic cements containing SCMs over plain cements in minimizing sulphate and chloride attack is mainly due to the following: (i) The pozzolanic reaction of SCMs, which reduces gypsum formation; (ii) low $\mathrm{C}_{3} \mathrm{~A}$ content, dilution effect; (iii) the reduction of $\mathrm{pH}$ value therefore, the ettringite becomes less expansive; (iv) the formation of additional amounts of $\mathrm{CSH}$, which produces a coating film on the alumina-rich and other reactive phases, thereby hindering the formation of secondary and lastly ettringite; and (v) the formation of secondary $\mathrm{CSH}$ also results in pore size refinement, which reduces the permeability as well as the ingress of aggressive ions (Wong and Poole, 1988; Al-Dulaijan, 2007; Aye and Oguchi, 2011; Thomas et al., 2012).

The aggressive attack of sulphate and chloride ions is one of the factors responsible for damage to concrete.
The corrosive action of chlorides is due to the formation of chloroaluminate hydrate, $\mathrm{C}_{3} \mathrm{~A} \cdot \mathrm{CaCl}_{2} \cdot 10 \mathrm{H}_{2} \mathrm{O}$, commonly known as Friedel's salt, which causes softening of concrete. The formed $\mathrm{CaCl}_{2}$ from the reaction of $\mathrm{MgCl}_{2}$ with the liberated lime increases the solubility of $\mathrm{Ca}(\mathrm{OH})_{2}$ that permits leaching. Thus, brucite $\left(\mathrm{Mg}(\mathrm{OH})_{2}\right)$ dissociates C-S-H and produces $\mathrm{Ca}(\mathrm{OH})_{2}$ and silica gel. The later may react with $\mathrm{Mg}(\mathrm{OH})_{2}$ to form Magnesium Silicate Hydrates (M-S-H), which has no binding properties. Also, sulphate ions can enter into chemical reactions with certain constituents of concrete, producing sulphoaluminate hydrates, $\mathrm{C}_{4} \mathrm{~A} . \mathrm{S}_{3} \cdot \mathrm{H}_{32}$ (ettringite), gypsum and $\mathrm{M}-\mathrm{S}-\mathrm{H}$ which has little binding properties (Page and Page, 2007). All of these reactions are accompanied by decrease in strength.

The production of Sulphate Resisting Cement (SRC) is expected to increase, due to its high durability against the aggressive attack of sulphates in soils and ground water. Therefore, it could be argued that, it is theoretically ideal cement for massive structures exposed to seawater or ground water (Hewlett, 2004).

Durability of concrete with Sulfonated-Acetone Formaldehyde (SAF) condensate superplasticizer was studied using sulfuric acid at $\mathrm{pH}=4.0$ and magnesium sulphate at $\mathrm{pH}=6.5$ after 6 months of immersion. The use of SAF improved the resistance of concrete to the solutions which is a direct result of reducing the water absorption and the permeable pores of concrete. It was concluded that, the aggressive solutions did not have 
significant damage effect on the concrete mixtures incorporating SAF resin compared to the control mix (Pei et al., 2004). It was found that, the effectiveness of superplasticizers on concrete was strongly related to the adsorption behavior of the admixtures on cement particles, as well as the degree of hydration (Hsu et al., 1999).

The effect of temperature on the properties of cement pastes can be studied up to $800^{\circ} \mathrm{C}$. The change in the phase composition of the thermally treated cement pastes can be investigated by the XRD and SEM techniques. The elevated temperature reduces the cement paste-aggregate bonds, progressive breakdown of cement gel structure, loss in concrete load-bearing capacity, reduces durability and increases tendency of structural cracking. This deterioration can often reach a level at which the structure may have to be thoroughly renovated or completely replaced, depending on various factors such as: Humidity, rate of heating, temperature level, heating time, cooling mode after heating, applied load, type of mineral admixture and inclusion levels (Yazıc1 et al., 2012; Handoo et al., 2002; Aydın and Baradan, 2007; Lau and Anson, 2006).

The evaporable water is lost at $100-110^{\circ} \mathrm{C}$, whereas the interlayer $\mathrm{CSH}$ water and some of combined water from the CSH and sulfoaluminate hydrates lost at about $300^{\circ} \mathrm{C}$. Further decomposition of $\mathrm{CH}$ begins at about $400-550^{\circ} \mathrm{C}$. On cooling, the $\mathrm{CaO}$ is rehydrated to $\mathrm{Ca}(\mathrm{OH})_{2}$ with a volume expansion of $97 \%$ and formation of cracks. Tobermorite gel $(\mathrm{CSH})$ is decomposed at $900^{\circ} \mathrm{C}$ (El-Didamony et al., 2012).

Use of SCMs can reduce the thermal deterioration of cement paste, mortar and concrete which can react with the liberated $\mathrm{CH}$ forming excess $\mathrm{CSH}$, whiych more powerful and thermally stable than $\mathrm{CH}$. Therefore, pozzolanic cement blends are less affected to high temperature (Yazıc1 et al., 2012; Handoo et al., 2002; Aydin and Baradan, 2007; Lau and Anson, 2006; El-Didamony et al., 2012; Shui et al., 2010).

The aim of the present investigation is to evaluate the effectiveness of laboratory synthesized SAF condensate on the durability of SRC pastes incorporating $10 \% \mathrm{SF}$ immersed in $4 \% \mathrm{MgSO}_{4}$ or $4 \% \mathrm{MgCl}_{2}$ corrosive solutions up to one year as well as subjected to elevated temperatures up to $800^{\circ} \mathrm{C}$.

\section{Materials and Methods}

\section{Starting Materials}

The materials used in this investigation were Sulphate Resisting Cement (SRC) provided from Elmasria Cement Company and condensed Silica Fume (SF) from Ferrosilicon Alloys Company, (Edfo and Aswan, Egypt). The chemical composition of starting materials is shown in Table 1. The surface area of SRC determined by the Blaine air permeability method, was found to be $3488 \mathrm{~cm}^{2} / \mathrm{g}$ whereas that of silica fume is about $20 \mathrm{~m}^{2} / \mathrm{g}$.
The mineralogical composition of silica fume and preparation of Sulfonated Acetone-Formaldehyde (SAF) Resin are found in previous study by Osman and Al-Masry (2014).

\section{Preparation of Cement Pastes \\ Preparation of Dry Mixes}

The ingredients of each mix of Sulphate Resisting Cement (SRC) and $10 \mathrm{wt} \%$ silica fume were mixed for one hour with four balls using a mechanical roller to assure complete homogeneity. The samples were kept in airtight container.

\section{Mixing of Cement Paste}

The required amount of each dry mix was placed on a smooth, non-absorbent surface and a crater was formed in the center. The required amounts of mixing water as water of consistency containing the admixture with different dosages $(0.0,0.5,1.0,1.5$ and $2.0 \%$ of the water-admixture) were poured into the crater and the cement on the outer edges was turned into the crater by the aid of a trowel. The dry cement around the outside of the crater was slightly toweled over the mixture to absorb the water for about one minute. The mixing operation was then completed by continuous vigorous mixing for about three minutes by means of gauging trowel.

\section{Moulding}

Stainless steel $1 / 2$ inch cubic moulds were used to prepare the cement pastes. Freshly prepared cement paste was placed in the moulds into two approximately equal layers. Each layer was compacted and manually pressed until homogeneous specimen was obtained. After the top of the layer was compacted, the moulds were then vibrated for a few minutes to remove any air bubbles to get a better compaction of the prepared pastes. The surface of the paste was smoothed by the aid of thin edged trowel.

\section{Curing}

Immediately after moulding, the moulds were cured in humidity chamber at about $100 \%$ relative humidity at room temperature $23 \pm 1^{\circ} \mathrm{C}$ for $24 \mathrm{~h}$ then demoulded and cured under tap water up to the time of testing. In the present study, all mixes were moulded and divided into three sets which used in the following curing modes:

\section{Curing Under Tap Water}

One set of all cement pastes was cured under tap water immediately after demoulding to study the hydration characteristics after one, 3, 7, 28, 90 days (Osman and Al-Masry, 2014). 
Table 1. Chemical analysis of starting materials, (wt\%)

\begin{tabular}{lllllllllll}
\hline Oxides Material & $\mathrm{SiO}_{2}$ & $\mathrm{Al}_{2} \mathrm{O}_{3}$ & $\mathrm{Fe}_{2} \mathrm{O}_{3}$ & $\mathrm{CaO}$ & $\mathrm{MgO}$ & $\mathrm{SO}_{3}$ & $\mathrm{Na}_{2} \mathrm{O}$ & $\mathrm{K}_{2} \mathrm{O}$ & I.L & Total \\
\hline SRC & 21.40 & 3.67 & 5.05 & 64.73 & 1.50 & 2.05 & 0.30 & 0.22 & 2.60 & 99.70 \\
Silica fume & 94.81 & 0.16 & 0.84 & 0.89 & 0.49 & 0.08 & 0.20 & 0.05 & 2.43 & 99.95 \\
\hline
\end{tabular}

\section{Curing Under $4 \% \mathrm{MgSO}_{4} .7 \mathrm{H}_{2} \mathrm{O}$ or $\mathrm{MgCl}_{2} \cdot 6 \mathrm{H}_{2} \mathrm{O}$ Solution}

Another set of all cement pastes was cured under tap water for 28 days (zero time) then cured under 4\% $\mathrm{MgSO}_{4} \cdot 7 \mathrm{H}_{2} \mathrm{O}$ or $4 \% \mathrm{MgCl}_{2} \cdot 6 \mathrm{H}_{2} \mathrm{O}$ to investigate their resistance to these aggressive media at the desired testing times 1, 3, 6, 9 and 12 months respectively. The aggressive solution was renewed monthly to maintain constant concentration.

\section{Firing at $200-800^{\circ} \mathrm{C}$}

Last set of cement pastes was cured under tap water for 28 days, dried at $105^{\circ} \mathrm{C}$ for $24 \mathrm{~h}$ and fired at 200 $800^{\circ} \mathrm{C}$ in intervals of $100^{\circ} \mathrm{C}$ to investigate their firing resistance. The firing program is carried out in a muffle furnace with a rate of $10^{\circ} \mathrm{C} / \mathrm{min}$ for $2 \mathrm{~h}$ at each temperature and cooled to room temperature in the furnace.

\section{Methods of Investigation}

\section{Fire Resistance Determination}

The fire resistance of cement pastes was studied at $250,450,600$ and $800^{\circ} \mathrm{C}$ in a muffle furnace with soaking time for $2 \mathrm{~h}$. The cement pastes were kept to cool in the furnace then, the fire resistance was measured (ignition loss), bulk density, total porosity and compressive strength of each cement paste at a definite temperature.

A set of three cubes for each mix fired at an appropriate temperature were immersed in kerosene for $24 \mathrm{~h}$. Specimens were then weighed (weight of saturated sample) and reweighed suspended in kerosene (weight of suspended sample). Specimens were dried at $105^{\circ} \mathrm{C}$ for $24 \mathrm{~h}$ and weighed in air (dried weight).

The bulk density and total porosity were calculated as in case of water but using the density of kerosene $\left(0.8 \mathrm{~g} / \mathrm{cm}^{3}\right)$.

The Ignition loss illustrates the behavior of cement pastes after fire exposure and was assessed as the difference between the weights before and after ignition divided by ignited weight:

$$
\begin{aligned}
& \text { W eight before ignition - } \\
& \operatorname{lgnition} \operatorname{loss}, \% \frac{\text { Weight after ignition }}{\text { W eight after iginition }} \times 100
\end{aligned}
$$

The compressive strength measurements were done on a compressive strength machine of SEIDNER, Riedinger, Germany, with maximum capacity of $600 \mathrm{KN}$ forces (ASTM, 2007).

\section{Determination of Total Sulphate}

The total sulphate content was gravimetrically estimated by using one $\mathrm{g}$ of powdered sample dissolved in $5 \mathrm{~mL}$ of concentrated $\mathrm{HCl}, 100 \mathrm{~mL}$ of distilled water was added, then boiled for $5 \mathrm{~min}$, then filtered and washed several times with distilled water. Ten milliliters of $10 \% \mathrm{BaCl}_{2}$ was added to the filtrate, which was digested, filtered and ignited at $1000^{\circ} \mathrm{C}$ for $30 \mathrm{~min}$. The total sulphate content was calculated as:

$$
\mathrm{SO}_{3} \%=\frac{\text { Weight of ppt }}{\mathrm{M}} \times 34.3
$$

where, $M$ is the weight of sample in grams.

\section{Determination of Total Chloride}

Total chloride content was determined in the hardened pastes by weighing $2 \mathrm{~g}$ sample into a stopper conical flask. The specimen was dispersed with $25 \mathrm{~mL}$ water and then added with $10 \mathrm{~mL}$ of nitric acid (sp. gr. 1.42). Fifty milliliters of hot water was added, heated to near boiling and kept warm for 10 to $15 \mathrm{~min}$. If the supernatant liquid is turbid, it was filtered through a rapid paper (41 filter paper) and washed with hot water and then cooled to room temperature. An excess of standard $0.1 \mathrm{~N}$ AgNO3 (16.98 g pure dry $\mathrm{AgNO}_{3}$, in liter) was added and 2-3 $\mathrm{mL}$ of nitrobenzene to stopple the flask, then vigorously shaken to coagulate the precipitate, then $1 \mathrm{~mL}$ ammounium ferric alum as indicator and titrate against standard $0.1 \mathrm{~N}$ ammonium thiocyanate.

\section{Results and Discussion}

\section{Effect of Treatment Temperature}

The effect of temperature on the properties of cement pastes admixed with various dosages of SAF can be studied by the determination of the weight loss, bulk density, total porosity and compressive strength of hardened cement pastes treated up to $800^{\circ} \mathrm{C}$.

\section{Weight Loss}

The weight loss of cement pastes admixed with various dosages of $\mathrm{SAF}$ as a function of treatment temperature up to $800^{\circ} \mathrm{C}$ is represented in Fig. 1. The weight loss increases with treatment temperature. This is mainly due to the decomposition of some hydration products (Cook and Hover, 1999). The free water is removed at $105^{\circ} \mathrm{C}$, a partial decomposition of calcium silicate hydrate and sulphoaluminate hydrates occurred around $200^{\circ} \mathrm{C}$. Moreover, the decomposition of 
gehlenite hydrate $\left(\mathrm{C}_{2} \mathrm{ASH}_{8}\right)$ is occurred above $200^{\circ} \mathrm{C}$ and dehydration of calcium hydroxide at $400-500^{\circ} \mathrm{C}$ (Cook and Hover, 1999). Also, the decomposition of calcium carbonate at temperature $750-800^{\circ} \mathrm{C}$ is occurred.

On the other side, as the amount of SAF increases up to $1.5 \mathrm{wt} \%$ the weight loss increases due to the acceleration of hydration. This leads to increase the hydration products. The weight loss decreases at 2.0 $\mathrm{wt} \% \mathrm{SAF}$ due to the retardation effect which leads to decrease the hydration products as well as the decrease of mixing water. The increase of the weight loss of cement pastes at all treatment temperature may be due to the absence of accelerator which accelerates the hydration and the decrease of free water.

\section{Bulk Density}

The bulk density of cement pastes admixed with various dosages of SAF as a function of treatment temperature is graphically plotted in Fig. 2. The results indicate that the bulk density of cement pastes decreases with the treatment temperature up to $250^{\circ} \mathrm{C}$. This is related to the removal of the free as well as some of bound water leaving pores that leads to decrease the density.

Generally, the bulk density for all cement pastes increases up to $600^{\circ} \mathrm{C}$ due to the reaction of silica fume with the decomposed lime forming more cementitious materials that fill some of the open pores. As the temperature increases up to $800^{\circ} \mathrm{C}$ the bulk density sharply increases due to the activation of hydration with the treatment temperature forming extra cementitious materials. On the other side, as the amount of SAF increases up to $1.5 \mathrm{wt} \%$ the bulk density increases due to the acceleration of hydration. The bulk density decreases at $2.0 \mathrm{wt} \% \mathrm{SAF}$ due to the retardation effect that decreases the hydration products and then the bulk density.

\section{Total Porosity}

The Total porosity of cement pastes admixed with various dosages of SAF as a function of treatment temperature is plotted in Fig. 3.

The total porosity decreases with the treatment temperature up to $250^{\circ} \mathrm{C}$. This is attributed to that the treatment temperature enhances the hydration of cement clinker phases as well as the reaction of silica fume with $\mathrm{CH}$ liberated from the hydration of Portland cement to form additional hydration products that fill more pores (Radwan et al., 2011; Komonen and Penttala, 2003). Therefore, the total porosity decreases.

Obviously, the total porosity increases sharply from $250^{\circ} \mathrm{C}$ up to $800^{\circ} \mathrm{C}$ for all cement pastes as a result of the formation of microcracks which result from the dehydration of $\mathrm{CH}$ crystals, the decomposition of calcium carbonate, increase vapor pressure of steam and crystal transformation of pozzolana as well as increase of crystallinity of the formed hydrates leading to a sort of opening of the pore system of cement paste (Komonen and Penttala, 2003). On the other hand, as the amount of SAF increases up to $2.0 \mathrm{wt} \%$ the total porosity increases due to the retardation effect.

\section{Compressive Strength}

Figure 4 shows the compressive strength of thermally treated cement pastes admixed with SAF up to 2.0 mass \% cured up to 28 days, then subjected to elevated temperature up to $800^{\circ} \mathrm{C}$.

The compressive strength of cement pastes increases as a result of enhancing the hydration of unhydrated cement clinker (Walters and Jones, 1991) as well as the improvement of pozzolanic reaction of silica fume with free lime to form extra $\mathrm{CSH}$ that has low $\mathrm{Ca} / \mathrm{Si}$ ratio with high strength (Walters and Jones, 1991).

This is also occurred by the internal autoclaving effect that builds up as a result of flow of steam produced from elimination of capillary, physically adsorbed and combined water at high temperature that increases the pressure which accelerates the hydration (Chan and Anson, 1999; Mohammed et al., 2014a; Piasta et al., 1984).

The compressive strength increases with the treatment temperature up to $600^{\circ} \mathrm{C}$ due to the pozzolanic reaction of silica fume with the decomposed $\mathrm{CaO}$ to produce more $\mathrm{C}-\mathrm{S}-\mathrm{H}$ which deposits in the pore system and forms more dense structure. However, the decrease of the compressive strength at $800^{\circ} \mathrm{C}$ may be ascribed to the decomposition of cementitious materials as well as the $\mathrm{CaCO}_{3}$.

On the other side, as the amount of SAF increases up to $1.5 \mathrm{wt} \%$ the compressive strength increases due to the acceleration of hydration. This leads to increase the hydration products. The compressive strength decreases at $2.0 \mathrm{wt} \% \mathrm{SAF}$ due to the retardation effect which leads to decrease the hydration products.

\section{Aggressive Attack on Cement Pastes}

The presence of sulphate or chloride ions in water leads to an aggressive behavior towards concrete because some constituents of the cement can enter into deleterious chemical reactions with these ions. Sulphates of various bases attack hardened cements very markedly. Magnesium, sodium, potassium, ammonium and various other sulphates react with both free calcium hydroxide in set cement to form calcium sulphate and with its hydrated calcium aluminates to form the more insoluble calcium sulphoaluminate hydrates. The reactions with sodium sulphate, for example, can be formulated as:

$$
\begin{aligned}
& \mathrm{Ca}(\mathrm{OH})_{2}+\mathrm{Na}_{2} \mathrm{SO}_{4} \cdot 10 \mathrm{H}_{2} \mathrm{O} \rightarrow \mathrm{Ca} \mathrm{SO}_{4} 2 \mathrm{H}_{2} \mathrm{O} \\
& +2 \mathrm{NaOH}+8 \mathrm{H}_{2} \mathrm{O} \\
& \quad 3 \mathrm{CaO} \cdot \mathrm{Al}_{2} \mathrm{O}_{3} \cdot 12 \mathrm{H}_{2} \mathrm{O}+3\left(\mathrm{CaSO}_{4} \cdot 2 \mathrm{H}_{2} \mathrm{O}\right) \\
& +13 \mathrm{H}_{2} \mathrm{O} \rightarrow 3 \mathrm{CaO} \cdot \mathrm{Al}_{2} \mathrm{O}_{3} \cdot 3 \mathrm{CaSO}_{4} \cdot 31 \mathrm{H}_{2} \mathrm{O}
\end{aligned}
$$


The alkali sulphates do not attack hydrated calcium silicates to any appreciable extent, they are more insoluble than the calcium sulphate and alkali silicates which would result.

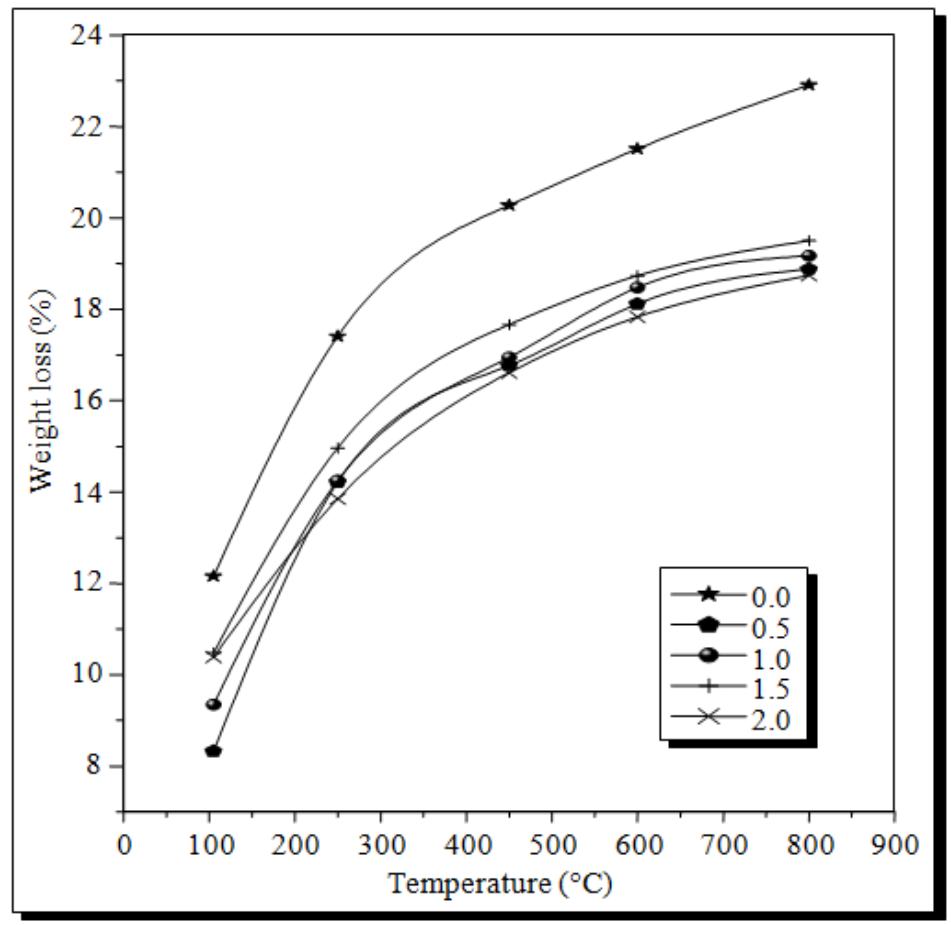

Fig. 1. The weight loss of cement pastes in presence of different dosages of SAF as a function of treatment temperature

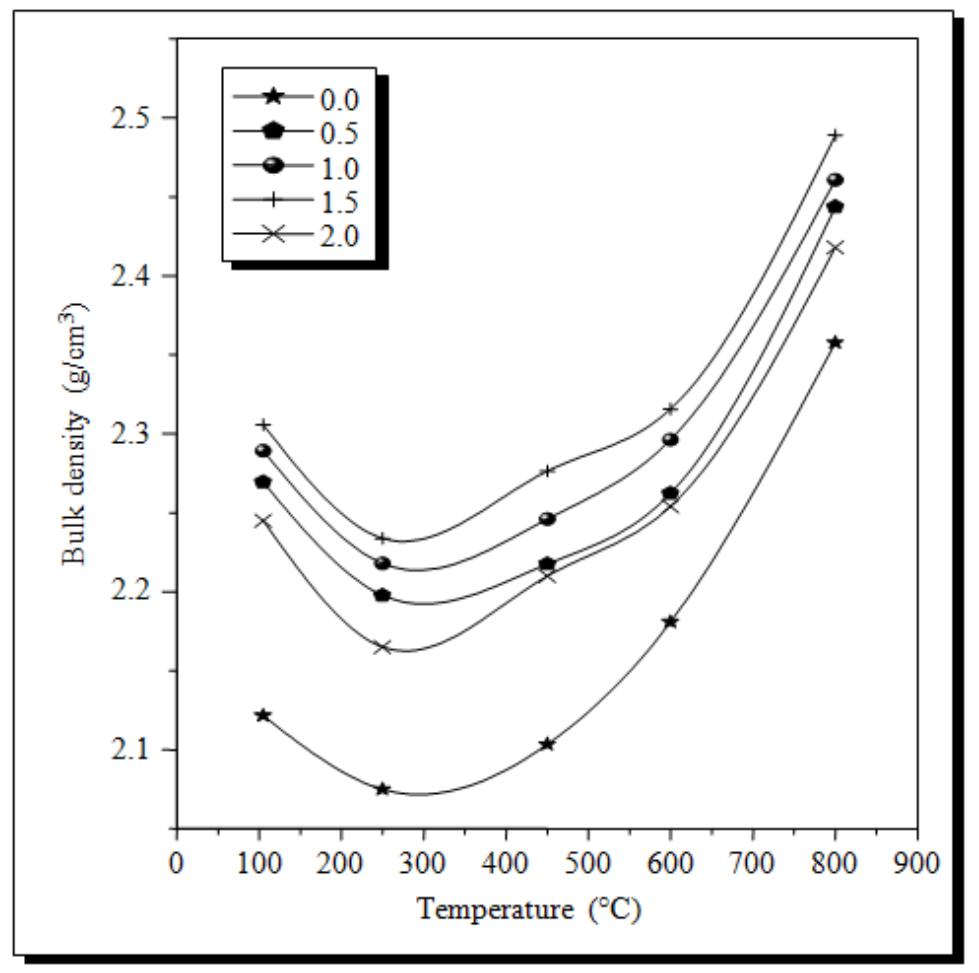

Fig. 2. The bulk density of cement pastes in presence of different dosages of SAF as a function of treatment temperature 


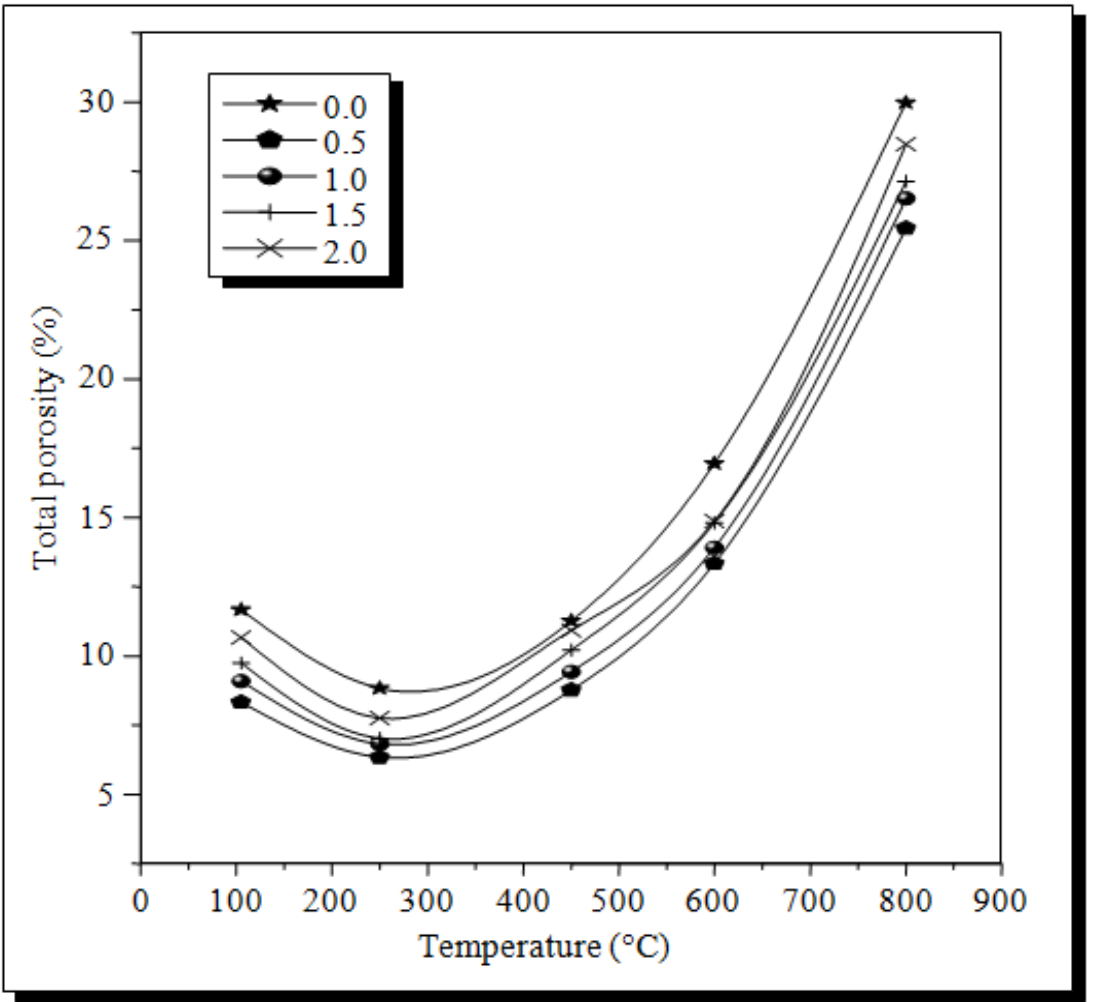

Fig. 3. The Total porosity of cement pastes in presence of different dosages of SAF as a function of treatment temperature

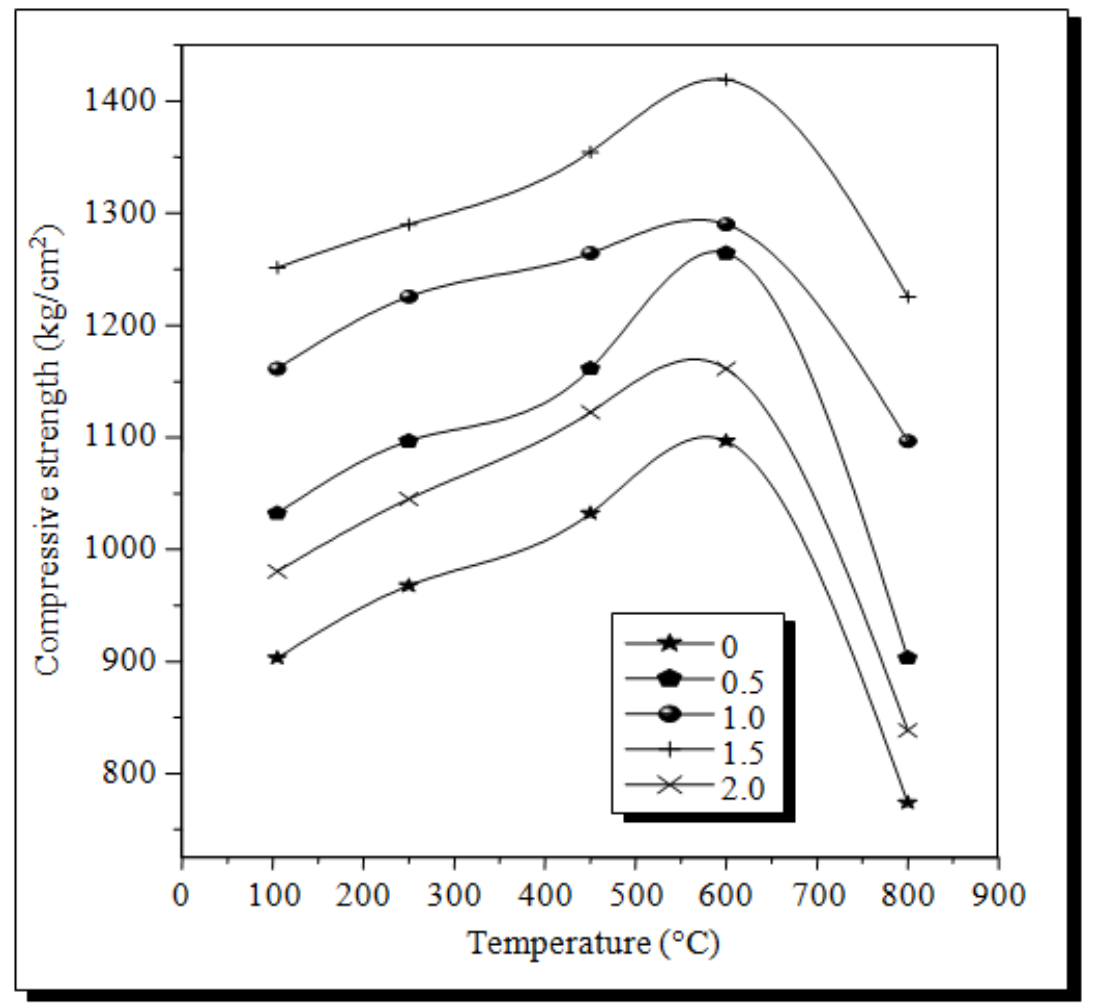

Fig. 4. The compressive strength of cement pastes in presence of different dosages of SAF as a function of treatment temperature 
Magnesium sulphate has a more far-reaching action that other sulphates and decomposes the hydrated calcium silicates in addition to reacting with the aluminates and calcium hydroxide. If tri- or $\beta$ dicalcium silicate is placed in a magnesium sulphate solution, formation of gypsum crystals occurs rapidly. The hydrated calcium silicates react in the following general manner:

$$
\begin{aligned}
& 3 \mathrm{CaO} .2 \mathrm{SiO}_{2} \cdot 3 \mathrm{H}_{2} \mathrm{O}+3\left(\mathrm{MgSO}_{4} 7 \mathrm{H}_{2} \mathrm{O}\right) \rightarrow \\
& 3\left(\mathrm{CaSO}_{4} \cdot 2 \mathrm{H}_{2} \mathrm{O}\right)+3 \mathrm{Mg}(\mathrm{OH})_{2}+2 \mathrm{SiO}_{2} \text { gel }
\end{aligned}
$$

The reason why this reaction proceeds completely, while with sodium sulphate does not occur, is to be found in the low solubility of magnesium hydroxide and resulting low $\mathrm{pH}$ value of its saturated solution (Greene, 1962; Mohammed et al., 2014b; Radwan et al., 2012a; Yeon et al., 2013; Radwan et al., 2012b; Fiertak and Stryszewska, 2013). The hydrated magnesium silicate appears to have no binding power, in contrast to calcium silicate hydrate and its formation represents therefore a final stage in the deterioration of concrete attacked by magnesium sulphate solution.

The effect of $4 \% \mathrm{MgSO}_{4}$ and $4 \% \mathrm{MgCl}_{2}$ on cement pastes admixed with various dosages of Sulfonated Acetone Formaldehyde (SAF) up to one year has been studied. The cubes of cement pastes were immersed in distilled water for 28 days (Zero time), then immersed under the aggressive medium up to one year. The solutions were renewed every month to keep the concentration nearly constant. The relative resistance of hardened cement pastes against the aggressive solutions was assessed by determining compressive strength, bulk density, total porosity, total sulphate and total chloride contents of the attacked cement pastes.

\section{Magnesium Sulphate Solution}

\section{Bulk Density}

Bulk density of the cement pastes admixed with various dosages of Sulfonated Acetone Formaldehyde (SAF) immersed under $4 \% \mathrm{MgSO}_{4}$ solution up to one year are graphically represented in Fig. 5. The results show that bulk density of different cement pastes increases up to 1 month and then decreases up to one year. The increase of bulk density for all cement pastes is due to activation action of sulphate solution and formation of additional hydration products which precipitated into the pores of the pastes and therefore the bulk density increases. The decrease of bulk density after 1 month is due to formation of ettringite crystals, which tend to grow and expand resulting in internal stresses that causes low bulk density. Also, $\mathrm{MgSO}_{4}$ reacts with the liberated $\mathrm{Ca}(\mathrm{OH})_{2}$ and deposits $\mathrm{Mg}(\mathrm{OH})_{2}$ with the decomposition of $\mathrm{CSH}$, which can be decomposed by
$\mathrm{MgSO}_{4}$. These two reactions lead to decrease bulk density of the hardened cement pastes. As the amount of the SAF increases up to $2.0 \mathrm{wt} \%$ the bulk density increases due to the filling effect and the acceleration of hydration; more hydration products are formed and then the pores decreases between the cement particles to produce more compact structure.

\section{Total Porosity}

The results of total porosity of cement pastes admixed with various dosages of SAF immersed under $4 \% \mathrm{MgSO}_{4}$ solution up to one year are shown Fig. 6 . It is clear that the total porosity of different cement pastes decreases up to 1 month and then increases up to one year. The decrease of total porosity for all cement pastes is due to the precipitation of the hydration products in the open pores that leads to decrease the total porosity. The increase of total porosity after 1 month may be due to the formation of gypsum and ettringite which are formed due to the action of sulphate solution. The ettringite gives expansion and then the total porosity increases. Consequently there is no disruption, but only increase in total porosity. On the other side, as the amount of SAF increases up to $2.0 \mathrm{wt} \%$ the corresponding total porosity decreases. This is due to the acceleration of hydration which forming more hydration products precipitated in the open pores of the cement pastes.

\section{Compressive Strength}

The compressive strength values of hardened cement pastes admixed with various dosages of SAF immersed under $4 \% \mathrm{MgSO}_{4}$ solution up to one year are shown Fig. 7. It is clear that the compressive strength of different cement pastes increases up to 1 month and then decreases up to one year. The increase of compressive strength is regarded to the progress of hydration as well as sulfate ions activate the hydration of cement pastes and formation of ettringite which fill some of pores and then the compressive strength increases (Chindaprasirt et al., 2014; Binici et al., 2012). The decrease of compressive strength after 1 month may be due to that the sulfate ions migrate from the aggressive medium to the interior of the hardened cement pastes and react with calcium aluminate hydrate and ferrite forming ettringite and/or monosulfate hydrate which expands at later ages causing cracks and deterioration of cement paste. Also $\mathrm{MgSO}_{4}$ reacts with $\mathrm{CSH}$ to produce gypsum, silica gel and brucite (Ye et al., 2014). Gypsum reacts at later ages with $\mathrm{C}_{3} \mathrm{AH}_{6}$ to form additional amounts of ettringite and/or monosulfate hydrate whereas brucite attacks $\mathrm{CSH}$ to form $\mathrm{CH}$ and $\mathrm{MSH}$ which has no binding properties. As the amount of SAF increases up to $2.0 \mathrm{wt} \%$ the compressive strength increases. This is mainly due to the acceleration of hydration which increases the amount of hydration products especially 
tobermorite-like gel (CSH). Generally, as the amount of accelerator increases the hydration of cement paste enhances and then the pozzolanic reaction between SF and $\mathrm{CH}$ increases. Therefore, the bulk density and compressive strength increases as well as the total porosity of the cement paste decreases.

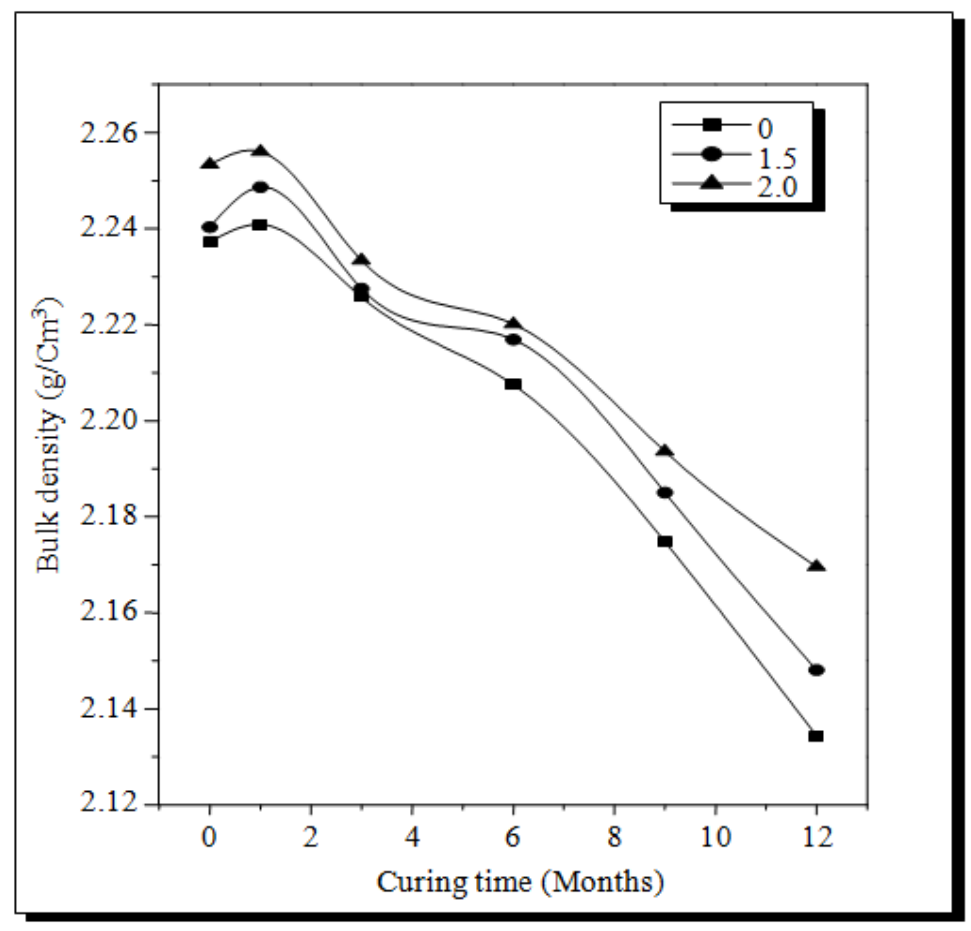

Fig. 5. Bulk density of cement pastes in presence of different dosages of SAF immersed under $4 \% \mathrm{MgSO}_{4}$ solution up to one year

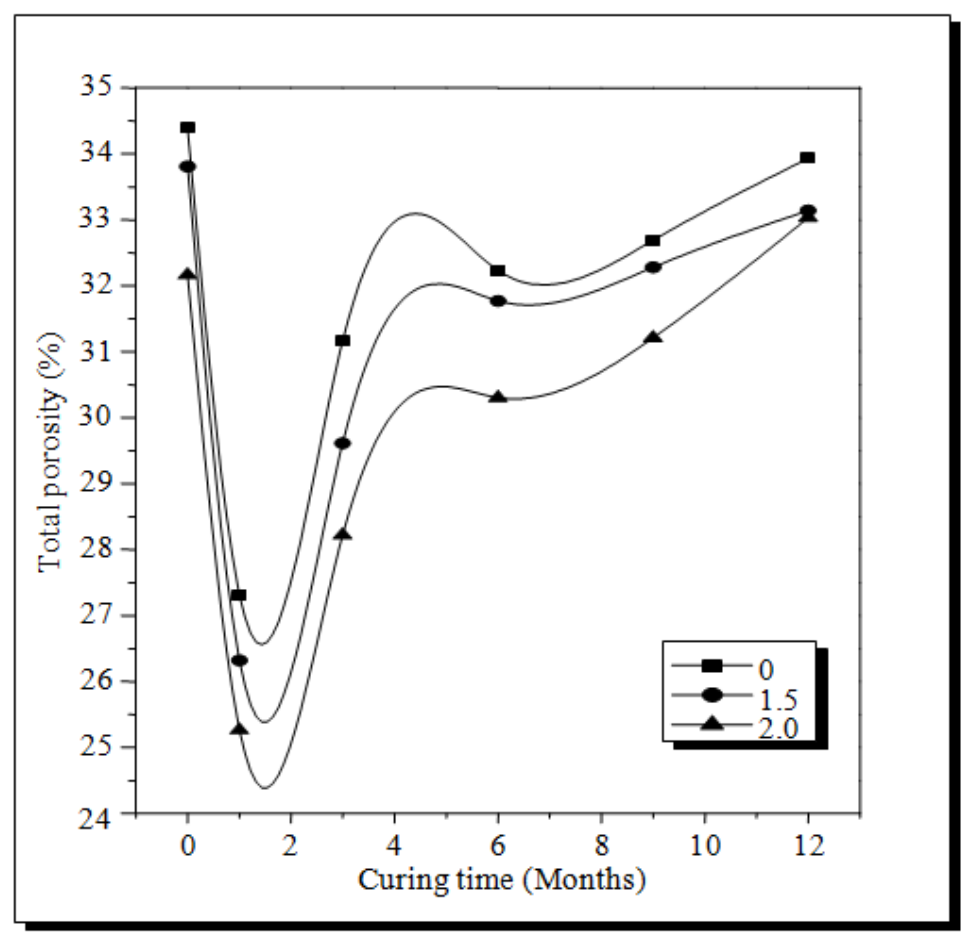

Fig. 6. Total porosity of cement pastes in presence of different dosages of SAF immersed under $4 \% \mathrm{MgSO}_{4}$ solution up to one year 


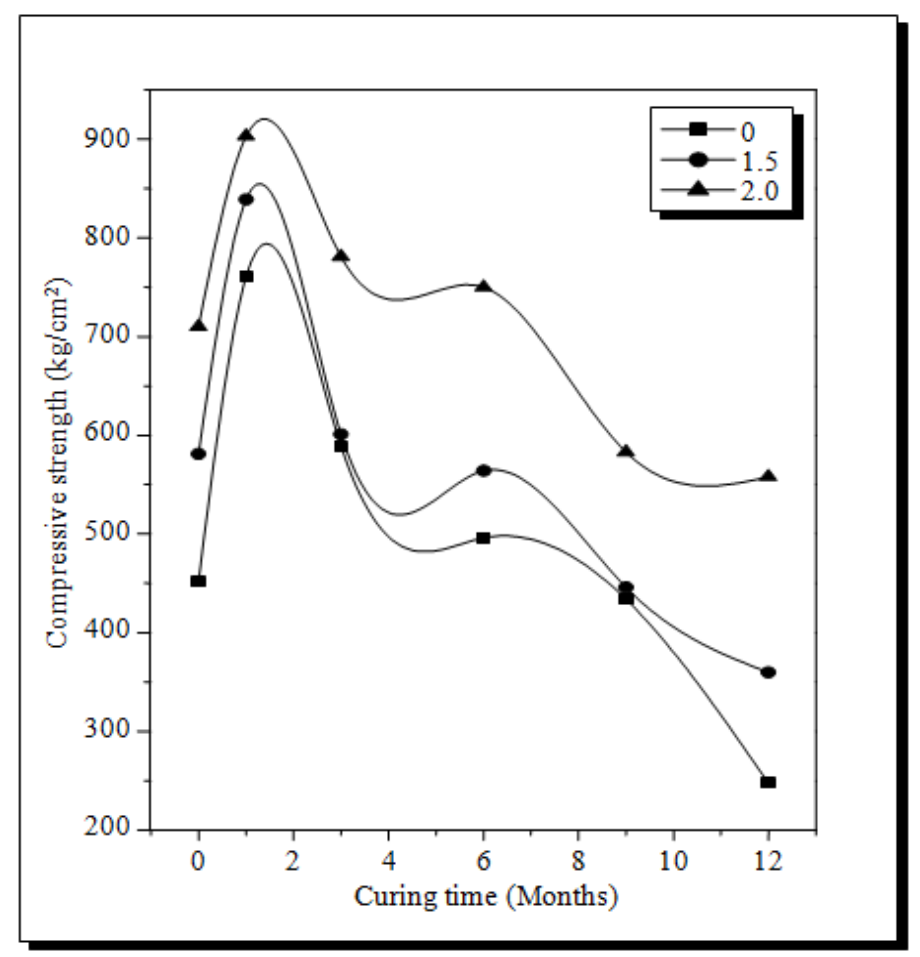

Fig. 7. Compressive strength of cement pastes in presence of different dosages of SAF immersed under $4 \% \mathrm{MgSO}_{4}$ solution up to one year

\section{Total Sulphates}

The total sulphate of cement pastes admixed with various dosages of SAF immersed under $4 \% \mathrm{MgSO}_{4}$ solution up to one year are given in Fig. 8. It is clear that the total sulphate content increases with immersing time up to one year. This is mainly due to the migration of the sulphate ions from the aggressive medium $\left(\mathrm{MgSO}_{4}\right.$ solution) to the cement pastes which reacts with $\mathrm{C}_{3} \mathrm{~A}$ and $\mathrm{Ca} \quad(\mathrm{OH})_{2}$ forming ettringite and/or calcium monosulphoaluminate hydrate. Also, $\mathrm{MgSO}_{4}$ reacts with calcium silicate hydrate to produce gypsum, silica gel and $\mathrm{Mg}(\mathrm{OH})_{2}$. Gypsum produced reacts furtherly with $3 \mathrm{CaO} . \mathrm{Al}_{2} \mathrm{O}_{3} \cdot 6 \mathrm{H}_{2} \mathrm{O}$ to form calcium sulphoaluminate hydrate (ettringite) and/or monosulphate hydrate. As the amount of the SAF increases up to $2.0 \mathrm{wt} \%$ the total sulphate content decreases due to the acceleration of hydration; more hydration products are formed and then the pores decreases between the cement particles to produce more compact structure. This is confirmed from the bulk density, total porosity and compressive strength.

\section{Magnesium Chloride Solution}

\section{Bulk Density}

The results of bulk density of cement pastes admixed with various dosages of SAF immersed under $4 \% \mathrm{MgCl}_{2}$ solution up to one year are graphically plotted in Fig. 9. It is clear that bulk density of all cement pastes increases up to 6 months and then decreases up to one year. The increase of bulk density up to 6 months is due to the accelerating action of chloride to the hydration of calcium silicate or calcium aluminate hydrates. So, these hydration products will precipitate into the pores of the paste which lead to increase the bulk density. The decrease of bulk density after 6 months up to one year for all cement pastes is mainly due to the formation of hydration products such as chloroaluminate hydrate which decreases the bulk density. As the amount of the SAF increases up to 2.0 $w t \%$ the bulk density increases due to the filling effect and the acceleration of hydration; more hydration products are formed and then the pores decrease between the cement particles to produce more compact structure.

\section{Total Porosity}

Total porosity of cement pastes admixed with various dosages of SAF immersed under $4 \% \mathrm{MgCl}_{2}$ solution up to one year are given and graphically plotted in Fig. 10. The results show that total porosity of different cement pastes decreases up to 6 months and then increases up to one year. The decrease of total porosity for all cement pastes up to 6 months is due to the accumulation of the hydrated products which fill a part of the originally filled spaces. The increase of total porosity after 6 months up to one year is due to the formation of calcium chloroaluminate hydrate which makes softening, therefore, total porosity increases. This is also due to the formation of $\mathrm{Mg}(\mathrm{OH})_{2}$ as a gelatinous material that 
increases the total porosity. On the other side, as the amount of SAF increases up to $2.0 \mathrm{wt} \%$ the corresponding total porosity decreases. This is due to the acceleration of hydration which forming more hydration products precipitated in the open pores of the cement pastes.

\section{Compressive Strength}

The compressive strength of cement pastes admixed with various dosages of SAF immersed under $4 \% \mathrm{MgCl}_{2}$ solution up to one year are given in Fig. 11. It is clear that the compressive strength of all cement pastes increases up to 6 months and then decreases up to one year. The increase of compressive strength is attributed to that chloride ions activate the hydration of cement. Hence formed hydration products fill some of pores then the total porosity decreases and compressive strength enhances. The increase of compressive strength at early ages may be also due to the adsorption and incorporation of a part of $\mathrm{Mg}^{2+}$ ions in to the CSH particles which enhance the crystallization of $\mathrm{CSH}$ as well as the strength of cement paste. The compressive strength decreases for all cement pastes due to the combination of $\mathrm{MgCl}_{2}$ with $\mathrm{CH}$ forming $\mathrm{CaCl}_{2}$ and $\mathrm{Mg}(\mathrm{OH})_{2} \cdot \mathrm{CaCl}_{2}$ reacts with $\mathrm{C}_{3} \mathrm{~A}$ to form chloroaluminate hydrates. While $\mathrm{Mg}(\mathrm{OH})_{2}$ dissociates $\mathrm{CSH}$ to form $\mathrm{MSH}$ and $\mathrm{CH}$. Both of chloroaluminate hydrates and $\mathrm{MSH}$ possess no binding properties and are accompanied by softening and loss of strength, consequently, the strength of hardened cement pastes decrease. The values of bulk density and total porosity are in a good agreement with those of compressive strength at all ages of immersion. The amount of diffused $\mathrm{MgCl}_{2}$ increases with curing time and as a result, deterioration of cement paste enhanced. As the amount of SAF increases up to $2.0 \mathrm{wt} \%$ the compressive strength increases. This is mainly due to the acceleration of hydration which increases the amount of hydration products especially tobermorite-like gel (CSH).

\section{Total Chloride}

The total chloride contents of cement pastes admixed with various dosages of SAF immersed under $4 \% \mathrm{MgCl}_{2}$ solution up to one year are plotted in Fig. 12. The chloride content gradually increases with time up to one year for all cement pastes. This is due to the chemical reactions between chloride ions and the hydrated components, such as calcium aluminate ferrite and $\mathrm{Ca}$ $(\mathrm{OH})_{2}$. The diffusion process of chloride ions in cement pastes is influenced by the cement composition and total porosity. As the amount of the SAF increases up to 2.0 $\mathrm{wt} \%$ the total chloride content decreases due to the acceleration of hydration; more hydration products are formed and then the pores decreases between the cement particles to produce more compact structure. This is confirmed from the bulk density, total porosity and compressive strength. The reaction of $\mathrm{Cl}^{-}$ions goes with high rate at early ages due to the decrease of its radius. Therefore the $\mathrm{Cl}^{-}$content is sharply increases at early ages.

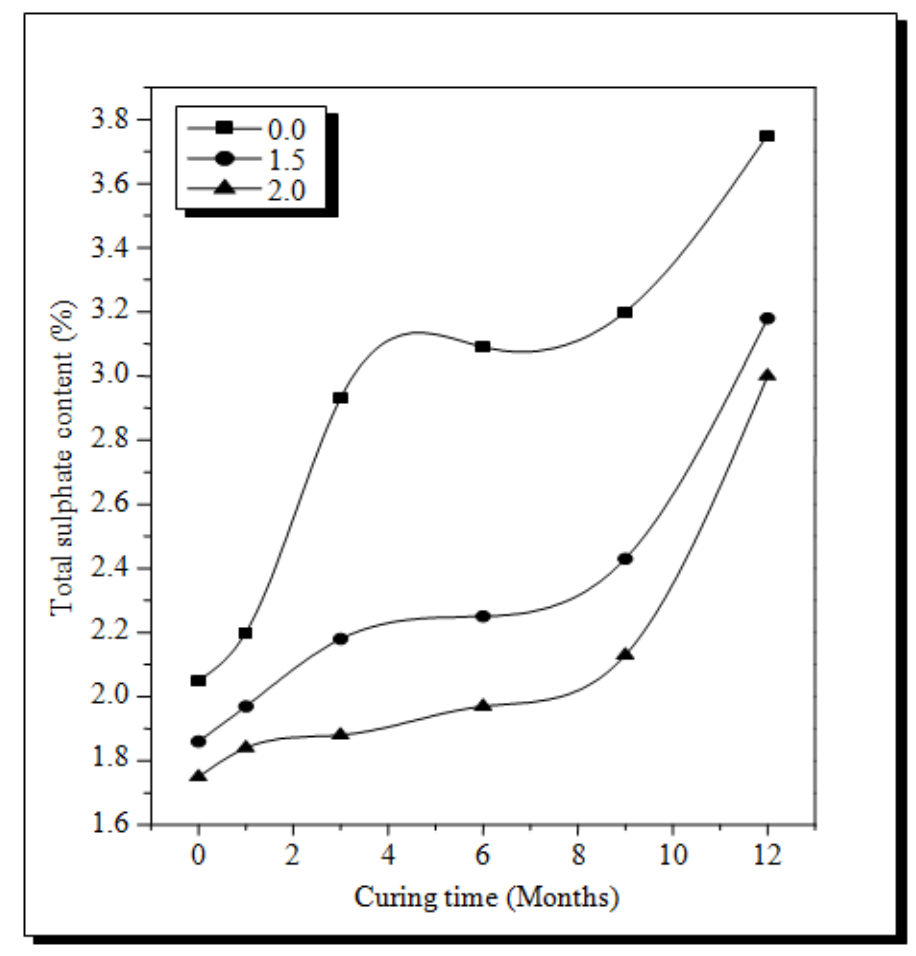

Fig. 8. Total sulphate content of cement pastes in presence of different dosages of SAF immersed under $4 \% \mathrm{MgSO}_{4}$ solution up to one year 


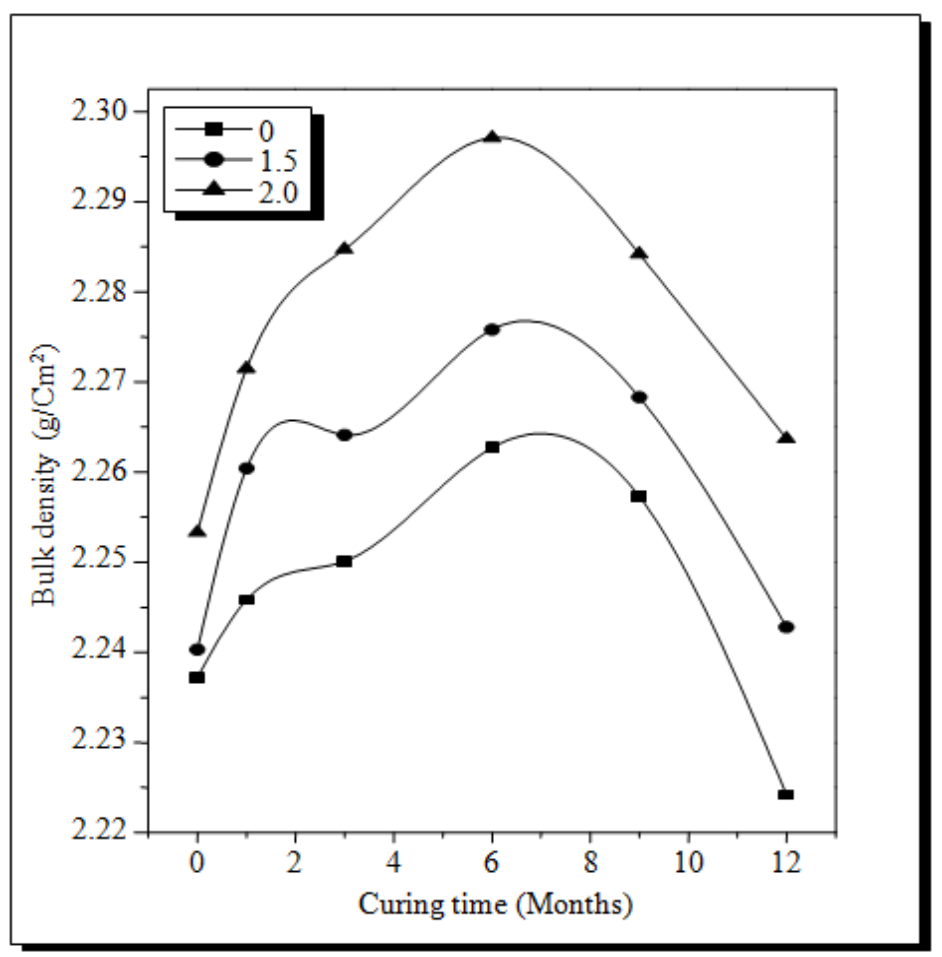

Fig. 9. Bulk density of cement pastes in presence of different dosages of $\mathrm{SAF}$ immersed under $4 \% \mathrm{MgCl}_{2}$ solution up to one year

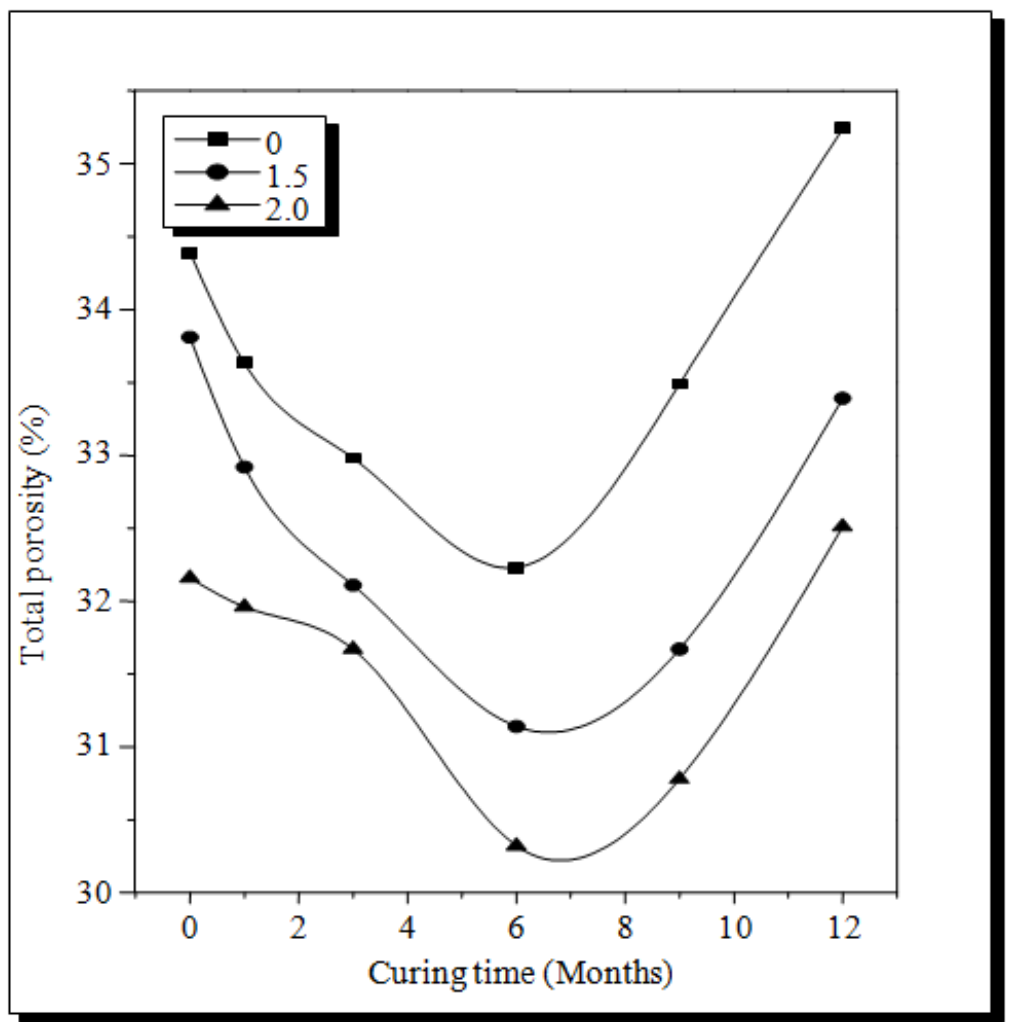

Fig. 10. Total porosity of cement pastes in presence of different dosages of SAF immersed under $4 \% \mathrm{MgCl}_{2}$ solution up to one year 


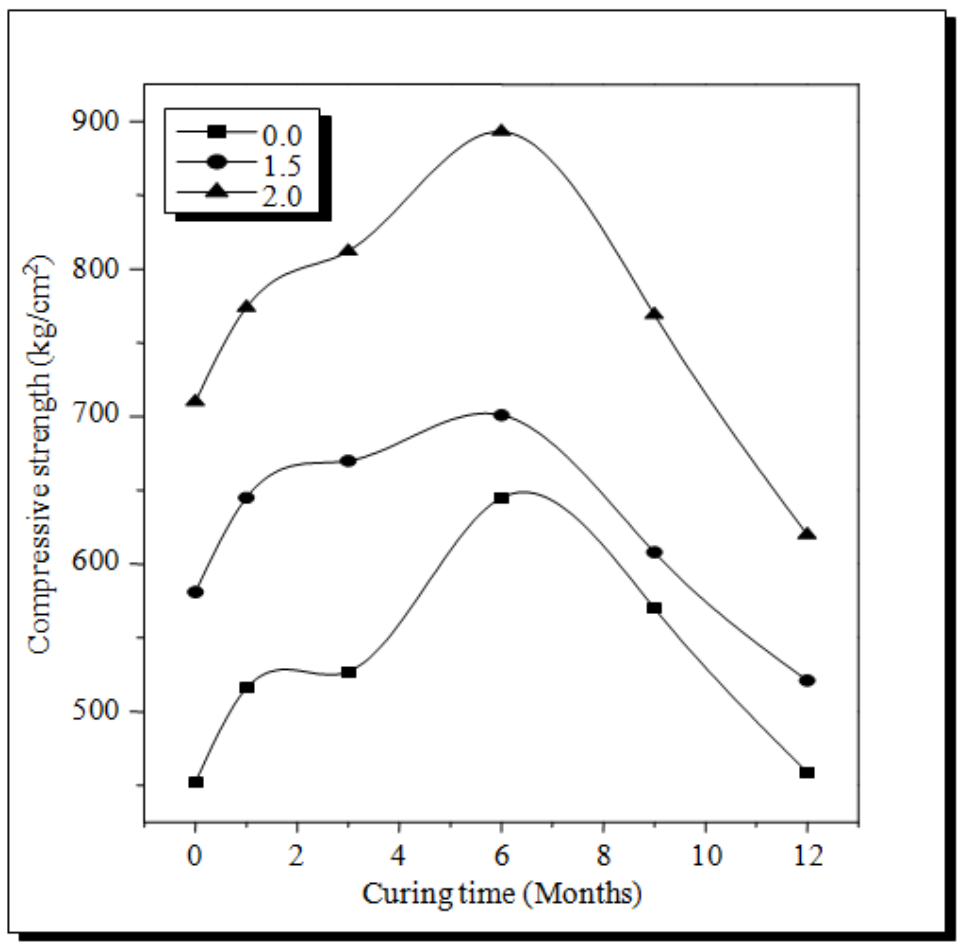

Fig. 11. Compressive strength of cement pastes in presence of different dosages of SAF immersed under $4 \% \mathrm{MgCl}_{2}$ solution up to one year

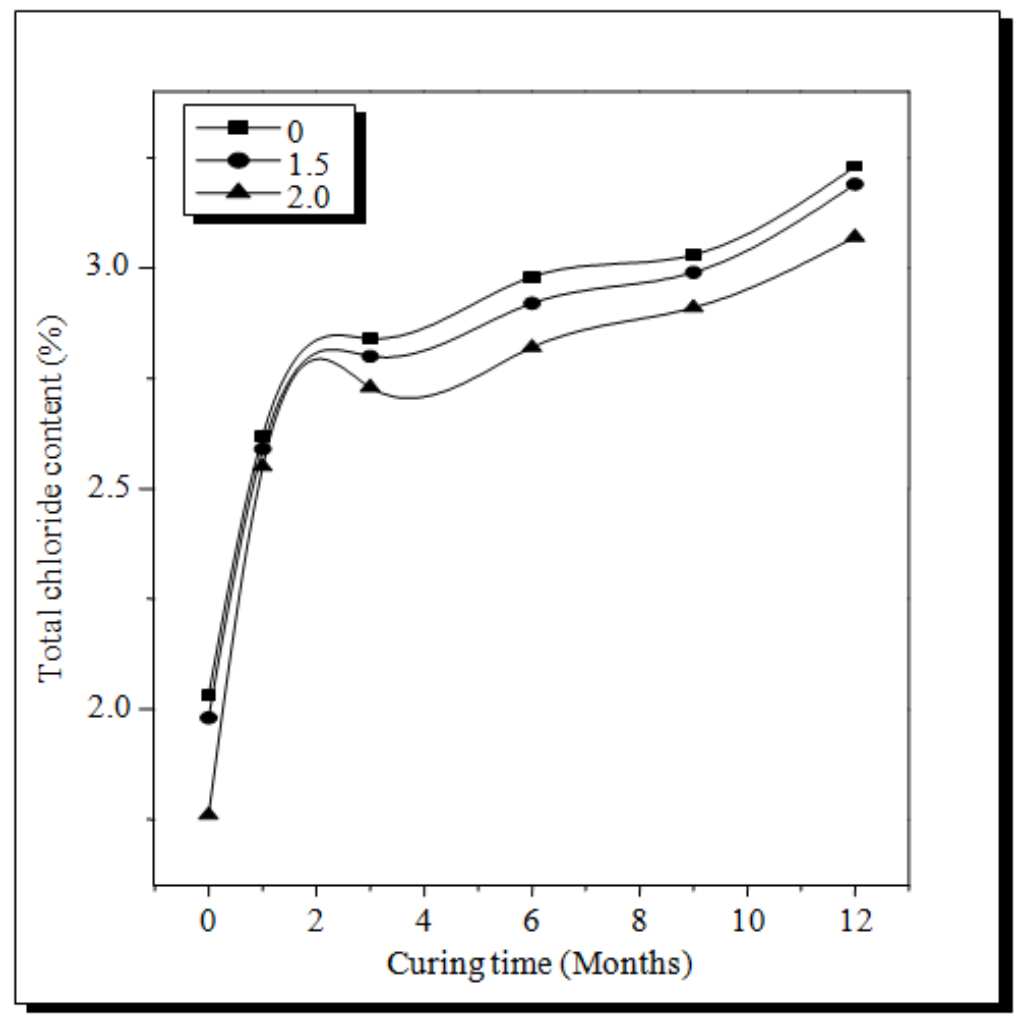

Fig. 12. Total chloride of cement pastes in presence of different dosages of $\mathrm{SAF}$ immersed under $4 \% \mathrm{MgCl}_{2}$ solution up to one year 


\section{Conclusion}

Based on the results of experimental study concerning the effectiveness of laboratory prepared SAF superplasticizer dosage up to 2 mass $\%$ on the hydration kinetics, total porosity, bulk density, compressive strength and durability of SRC pastes containing $10 \% \mathrm{SF}$ cured in salt solutions (immersed in $4 \% \mathrm{MgSO}_{4}$ or $4 \%$ $\mathrm{MgCl}_{2}$ ) and at elevated temperatures up to $800^{\circ} \mathrm{C}$. Several recommendations and conclusions can be derived and presented as follows:

- The total chloride and sulphate contents decrease with SAF content up to $2.0 \%$, due to the pozzolanic reaction of SF with $\mathrm{CH}$ forming additional calcium silicate hydrate to fills some open pores, thereby inhibiting the chloride and sulphate ions penetration

- The compressive strength of thermally treated cement pastes admixed with $1.5 \%$ SAF increases up to $600^{\circ} \mathrm{C}$ and then decreases up to $800^{\circ} \mathrm{C}$. The increase of compressive strength up to $600^{\circ} \mathrm{C}$ may be due to the acceleration of the hydration of pozzolanic reaction. The decrease at $800^{\circ} \mathrm{C}$ is due to the decomposition of cementitious materials and the coarsening of pore size distribution, which drastically increases the total porosity and decreases the bulk density

- $\quad$ SRC-SF composite admixed with $1.5 \%$ of SAF is more durable against fire up to $800^{\circ} \mathrm{C}$ and $4 \% \mathrm{Mg}$ $\mathrm{SO}_{4}$ or $4 \% \mathrm{MgCl}_{2}$ solutions

\section{Acknowledgement}

We gratefully acknowledge to the Faculty of Science, Zagazig University and National Research Centre due to the support to this research.

\section{Funding Information}

This research was internally supported.

\section{Author's Contributions}

All authors equally contributed in this work.

\section{Ethics}

This article is original and contains unpublished material. The corresponding author confirms that all of the other authors have read and approved the manuscript and no ethical issues involved.

\section{References}

Al-Dulaijan, S.U., 2007. Sulfate resistance of plain and blended cements exposed to magnesium sulfate solutions. Construct. Build. Mater., 21: 1792-802. DOI: 10.1016/j.conbuildmat.2006.05.017
ASTM, 2007. Standard test method for compressive strength of hydraulic cement mortars. ASTM Standars.

Aydın, S. and B. Baradan, 2007. Effect of pumice and fly ash incorporation on high temperature resistance of cement based mortars. Cement Concrete Res., 37: 988-995. DOI: 10.1016/j.cemconres.2007.02.005

Aye, T. and C.T. Oguchi, 2011. Resistance of plain and blended cement mortars exposed to severe sulfate attacks. Construct. Build. Mater., 25: 2988-2996. DOI: $10.1016 /$ j.conbuildmat.2010.11.106

Binici, H., S. Kapur, J. Arocena and H. Kaplan, 2012. The sulphate resistance of cements containing red brick dust and ground basaltic pumice with sub-microscopic evidence of intra-pore gypsum and ettringite as strengtheners. Cement Concrete Compos., 34: 279-287. DOI: 10.1016/j.cemconcomp.2011.10.001

Chan, S.Y.N. and G.F. Anson, 1999. Residual strength and pore structure of high-strength concrete and normal strength concrete after exposure to high temperatures. Cement Concrete Compos., 21: 1-23. DOI: 10.1016/S0958-9465(98)00034-1

Chen, X. and S. Wu, 2013. Influence of water-to-cement ratio and curing period on pore structure of cement mortar. Construct. Build. Mater., 38: 804-812. DOI: 10.1016/j.conbuildmat.2012.09.058

Chindaprasirt, P., P. Paisitsrisawat and U. Rattanasak, 2014. Strength and resistance to sulfate and sulfuric acid of ground fluidized bed combustion fly ash-silica fume alkali-activated composite. Adv. Powder Technol., 25: 1087-1093. DOI: $10.1016 /$ j.apt.2014.02.007

Cook, R.A. and K.C. Hover, 1999. Mercury porosimetry of hardened cement pastes. Cement Concrete Res., 29: 933-943. DOI: 10.1016/S0008-8846(99)00083-6

El-Didamony, H., E.A. El-Rahman and R.M. Osman, 2012. Fire resistance of fired clay bricks-fly ash composite cement pastes. Ceram. Int., 38: 201-209. DOI: 10.1016/j.ceramint.2011.06.050

Fiertak, M. and T. Stryszewska, 2013. resistance of three-component cement binders in highly chemically corrosive environments. Procedia Eng., 57: 278-286. DOI: 10.1016/j.proeng.2013.04.038

Greene, K.T., 1962. Early hydration reactions of portland cement. Proceedings of the 4th International Symposium on the Chemistry of Cement, (SCC' 62), Washington, pp: 359-374.

Handoo, S.K., S. Agarwal and S.K. Agarwal, 2002. Physicochemical, mineralogical and morphological characteristics of concrete exposed to elevated temperatures. Cement Concrete Res., 32: 1009-1018. DOI: 10.1016/S0008-8846(01)00736-0

Hewlett, P.C., 2004. Lea's Chemistry of Cement and Concrete. 4th Edn., Butterworth-Heinemann, Oxford ISBN-10: 0080535410, pp: 1092. 
Hsu, K.C., J.J. Chiu, S.D. Chen and Y.C. Tseng, 1999. Effect of addition time of a superplasticizer on cement adsorption and on concrete workability. Cement Concrete Compos., 21: 425-430. DOI: 10.1016/S0958-9465(99)00030-X

Irassar, E.F., M.A. González and V.F. Rahhal, 2000. Sulphate resistance of type V cements with limestone filler and natural pozzolana. Cement Concrete Compos., 22: 361-368.

DOI: 10.1016/S0958-9465(00)00019-6

Komonen, J. and V. Penttala, 2003. Effects of High Temperature on the pore structure and strength of plain and polypropylene fiber reinforced cement pastes. Fire Technol., 39: 23-34. DOI: 10.1023/A:1021723126005

Lau, A. and M. Anson, 2006. Effect of high temperatures on high performance steel fiber reinforced concrete. Cement Concrete Res., 36: 1698-1700.

DOI: 10.1016/j.cemconres.2006.03.024

Mohammed, M.S., A.E.S.I. Ahmed and R.M. Osman, 2014a. Microcrystalline cellulose as a reinforcement agent to cement pastes. Pigment Resin Technol., 43: 104-110. DOI: 10.1108/PRT-05-2013-0038

Mohammed, S.M., A.E.S.I. Ahmed, R.M. Osman and I. Khattab, 2014b. Combinations of organic and inorganic wastes for brick production. Polymer Compos., 35: 174-179. DOI: 10.1002/pc.22647

Montes, O.B., M. Palacios, P. Rivilla and F. Puertas, 2012. Compatibility between superplasticizer admixtures and cements with mineral additions. Construct. Build. Mater., 31: 300-309.

DOI: 10.1016/j.conbuildmat.2011.12.092

Osman, R.M. and S. Al-Masry, 2014. Impact of Sulfonated Acetone Formaldehyde (SAF) on the durability of SRC-SF composite cement pastes. Int. J. Adv. Scientific Tech. Res., 6: 426-443.

Page, C.L. and M.M. Page, 2007. Durability of Concrete and Cement Composites. 1st Edn., Woodhead and Maney on behalf of Institute of Materials, Cambridge, ISBN-10: 1855739402, pp: 404.

Pei, M., Y. Yang, X. Zhang, J. Zhang and J. Dong et al., 2004. Synthesis and the effects of water-soluble sulfonated acetone-formaldehyde resin on the properties of concrete. Cement Concrete Res., 34: 1417-1420. DOI: 10.1016/j.cemconres.2004.01.012

Piasta, J., Z. Sawicz and L. Rudzinski, 1984. Changes in structure of hardened cement pastes due to the high temperature. ACI Mater Constr., 17: 291-296. DOI: $10.1007 / \mathrm{BF} 02479085$

Radwan, A.M., E.A. El-Alfi and R.M. Othman, 2012a. Influence of substitution of ordinary portland cement by silica fume in the durability of slag portland cement pastes in sea water. ARPN J. Eng. Applied Sci., 7: 283-291.
Radwan, A.M., E.A. El-Alfi and R.M. Osman, 2012b. Characteristics of portland cement pastes with high replacement of slag. J. Eng. Applied Sci., 7: 338-344.

Radwan, A.M., R.M. Osman and H. Abu-El-Naga, 2011. Characteristics of building bricks made from altered basalt and de-aluminated kaolin. Int. Ceramic Rev., 60:130-133.

Sánchez, I., M.P. López, J.M. Ortega and M.A. Climent, 2011. Impedance spectroscopy: an efficient tool to determine the non-steady-state chloride diffusion coefficient in building materials. Mater. Corros., 62: 139-145. DOI: 10.1002/maco.201005775

Shanahan, N. and A. Zayed, 2007. Cement composition and sulfate attack: Part I. Cement Concrete Res., 37: 618-623. DOI: 10.1016/j.cemconres.2006.12.004

Shui, Z.H., R. Zhang, W. Chen and D.X. Xuan, 2010. Effects of mineral admixtures on the thermal expansion properties of hardened cement paste. Construct. Build. Mater., 24: 1761-1767. DOI: 10.1016/j.conbuildmat.2010.02.012

Thomas, M.D.A., R.D. Hooton, A. Scott and H. Zibara, 2012. The effect of supplementary cementitious materials on chloride binding in hardened cement paste. Cement Concrete Res., 42: 1-7. DOI: 10.1016/j.cemconres.2011.01.001

Walters, G.V. and T.R. Jones, 1991. Effect of metakaolin on Alkali-Silica Reaction (ASR) in concrete manufactured with reactive aggregates. Proceedings of the 2nd International Conference on Durability of Concrete, (CDC' 91), Montreal, pp: 941-947.

Wong, G.S. and T. Poole, 1988. Sulfate resistance of mortars using portland cement and blends of portland cement and pozzolan or slag. Technical Report SL-88-34, US Army Corps of Engineers, Washington, DC.

Yazıc1, S., G.I. Sezer and H. Şengül, 2012. The effect of high temperature on the compressive strength of mortars. Construct. Build. Mater., 35: 97-100. DOI: 10.1016/j.conbuildmat.2012.02.082

Ye, Q., C. Shen, S. Sun, R. Chen and H. Song, 2014. The sulfate corrosion resistance behavior of slag cement mortar. Construct. Build. Mater., 71: 202-209. DOI: 10.1016/j.conbuildmat.2014.08.019

Yeon, J.H., S. Choi and M.C. Won, 2013. In situ measurement of coefficient of thermal expansion in hardening concrete and its effect on thermal stress development. Construct. Build. Mater., 38: 306-315. DOI: 10.1016/j.conbuildmat.2012.07.111 